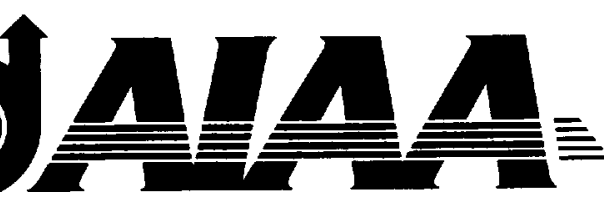

AIAA 2002-0171

\title{
A New Forced Oscillation Capability for the Transonic Dynamics Tunnel
}

David J. Piatak and Craig S. Cleckner NASA Langley Research Center Hampton, VA

\section{0th AIAA Aerospace Sciences Meeting \& Exhibit 14-17 January 2002 / Reno, NV}

For permission to copy or republish, contact the copyright owner named on the first page. For AIAA-held copyright, write to AIAA, Permissions Department, 1801 Alexander Bell Drive, Suite 500, Reston, VA 20191-4344. 
, 


\title{
A New Forced Oscillation Capability for the Transonic Dynanics Tunnel
}

\author{
David J. Piatak and C aig S. Cleckner \\ NASA Langley Res arch Center \\ Hampton. VA
}

\begin{abstract}
A new forced oscillation system has heen installed and tested at NASA Langley Research Center's Transonic Dynamics Tumnel (TDT). The system is known as the Oscillating Turntable (OTT) and has been designed for the purpose of oscillating. large semispan models in pitch at frequencies up to $40 \mathrm{~Hz}$ to accuire high-quality unsteady pressure and loads data. Precisely controlled motions of a wind-tunnel model on the OTT can yield unsteady aerodynamic phenomena associated with flutter, limit cycle oscillations, shock dynamics, and non-linear aerodynamic effects on many vohicle configurations. This paper will discuss the general design and components of the OTT and will present test data from performance testing and from research tests on two rigid semispan wind-tunnel nodels. The research tests were designed to challenge the OTT over a wide range of operating conditions while acquiring unsteady pressure data on a small rectangular supercritical wing and a large supersonic transport wing. These results will be presented to illustrate the performance capabilities. consistency of oscillations, and usefulness of the OTT as a research tool.
\end{abstract}

\section{INTRODUCTION}

Today, an aircraft's structure tends to be conservative in strength for many reasons, including the lack of accurate flutter prediction codes. If one can accurately predict the flutter and other aeroelastic characteristics of an aircraft before it is constructed. the aircraft wing structure could be optimized from the perspectives of flutter, strength, and weight. However, many incidences of aeroelastic shortcomings are identified and addressed after an aircraft's first flight due to the challenges, especially in the transonic regime. of predicting the complex interaction of aerodynamic: forces, elastic forces. and inertial forces. Accurate aeroelastic analyses require rigorous modelling of the unsteady acrodynamic environment at transonic speeds and high reduced frequencies.

(Copyright (c) 2002 by the American Inst it ute of Atronautics and Astromautics. Inc. No copyright is asserted in the Inited States under Tille 17, U.S. Cocte. The T.S. Guvernment has a royalty-free license to exercize all rights under the copyright claimed herein for Governmental purposes. All ot her rights are reserved by the copyright owner.
There are many flow phenomena associated with ae oelasticity that challenge todays aeroelastic analysi i methods, particularly the components of these an lyses simulating vehicle aorodynamics. At transou ic speeds, steady and unsteady aerodynamic effects ter d to reduce the flutter dynamic pressure of a vehic le and are difficult to predict accurately: Other challenging unsteady flow phenomena include shock dy ramics, shock induced flow separation, flow associated with limit cycle oscillations (LCO), vortical flow $\mathrm{du}$ : to high incidence angle and configuration. and various other nonlinear unsteady aerodynamic effects. To achieve the goal of improving the prediction of flutter an 1 other aeroelastic phenomena for future aircraft desigus, advancements must be made in the prediction of insteady pressures and the resulting loads on config arations oscillating at high reduced frequencies and at transonic speeds. ${ }^{1-3}$

Validation of and improvements to unsteady aerodyna nic analysis methods require experimental benchma rk data for correlation. To acquire such data. unst ady pressure measurements are typically made on su sscale wind-tunnel models while undergoing flutter or turing forced oscillations. There have been several stı dies which have measured unsteady pressures and loc ds on wind-tumnel models undergoing forced oscillations. References $t$ through 7 present such results fro m semispan rectangular planform wind-tumel models at frequencies up to $60 \mathrm{~Hz}$. but these experiments we re limited to small, rectangular wings with low pitch ine rtias. Reference 8 presents unsteady pressure and loc ds data from a relatively small. straked delta wing model oscillated in pitch at frequencies up to $16 \mathrm{~Hz}$. The majority. however. of available unsteady pressure da a has been acquired during flutter at frequencies on the order of $10 \mathrm{~Hz}$ or less. ${ }^{9-11}$ Under these conditic ns, the out-of-phase component of pressure is typica ly small and difficult to measure accurately. Many uin steady computations do not compare well with measu ed data for the out-of-phase component of pressure. $W$ th the given data, it is difficult to determine if this is 1 shortcoming of the theoretical methods employed. or errors in the measurements due to small amplitude pressure fluctuations. Tests at higher frequencies and os illation amplitudes should result in larger. more accu atcly measured. out-of-phase pressure amplitudes 
that will help answer these questions. Therefore, the ability to precisely oscillate large wind-tunnel models in pitch at a wide range of frecuencies and amplitudes while acquiring unsteady pressure data would answer these questions and ultimately benefit the prediction of flutter, limit cycle oscillations, shock dynamics, and other challenging aeroelastic and flow phenomena.

Such a forced oscillation system has been designed, installed, and tested at the Transonic Dynamics Tunnel (TDT) at NASA Langley Research Center for the purpose of oscillating large, semispan wind-tunnel models in pitch at frequencies up to $40 \mathrm{~Hz}$. The system is known as the Oscillating Turntable (OTT) and can be used to study flow phenomena associated with flutter. LCO, shock dynamics, and nonlinear unsteady aerodynamic effects on a wide variety of aerospace vehicle configurations at transonic speeds. The OTT's powerful hydraulic actuator system and digital servocontroller ensure precise control of model motion (oscillations, step inputs, and other user-defined motions) to provide high-quality unsteady pressure data for code validation and enhancement.

This paper will discuss the general design and components of the OTT, along with test data from OTT performance testing and from tests of two very different semispan wind-tunnel models. During performance testing, the OTT's hydraulic, electronic, and mechanical systems were evaluated while oscillating an inertia model. The inertia model was designed to simulate the maximum pitch inertia to be oscillated at $40 \mathrm{~Hz}$ and one degree amplitude. Tests of a small. rectangular, supercritical wing and a large, supersonic transport wing were intended to challenge the OTT over a wide range of operating conditions while, at the same time, acquiring unsteady pressure data. These results will be presented to illustrate OTT performance capabilities, consistency of oscillations, and the usefulness of the OTT as a research tool.

\section{TRANSONIC DYNAMICS TUNNEL DESCRIPTION}

The Langley Transonic Dynamics Tunnel (TDT) is a closed-circuit, continuous-flow, variable-pressure, transonic wind tumel with a $16-\mathrm{ft}$ square test section with cropped corners (Ref. 12). The TDT can be operated up to Mach 1.2 at pressures from near vacuum to atmospheric and in either air or heavy gas (R-134a) test mediums. Dynamic pressures up to 550 psf and Reynolds numbers up to 10 million/foot can be achieved in R-134a. Figure 1 is a cross section of the TDT at the test section and shows the relative positions of the plenum, test section. and the location of the OTT. Due to the high-risk nature of dynamic model testing, several features of the TDT have been designed to reduce risk so as to protect the model from destruction and also protect the facility from damage due to model debris. These features include a bypass valve system that quickly decreases dynamic pressure and Mach number in the test section to prevent model failure due to aeroelastic instability, large control room windows for viewing model dyuamics. and a tunnel drive fan protection screen designed to prevent model debris from damaging the fan blades.

\section{OSCILLATING TURNTABLE DESCRIPTION}

The OTT is a newly acquired research tool at the TDT that has been designed to oscillate large, semispan models in pitch at high frequencies and transonic: conditions. Models may he oscillated sinusoidally at constant or varying frequencies, be subjected to a step input, or undergo user-defined motion. It is anticipated that unsteady pressure measurements due to precisely controlled model motions will provide valuable data for CFD correlation and aircraft design with respect to flutter. limit cycle oscillations, and other unsteady aerodynamic/aeroelastic phenomena.

Figure 2 highlights key components of the OTT. The OTT utilizes a powerful rotary hydraulic actuator, rated for 495,000 in-lbf, and a digital Proportional. Integral, Derivative, Feedforward (PIDF) control system to position and oscillate models. Power for the OTT is supplied by a $3000 \mathrm{psi}, 150 \mathrm{gpm}$ hydraulic power unit which is located outside the tunnel pressure shell. Rails allow for precise positioning of the system with respect to the tunnel wall to accomodate a wide range of models and model support systems. Cam wheels and clamps lock the OTT onto its rails once it is in position to prevent the OTT from lifting off the rails during high-power oscillations. For model instrumentation, a 2.5 inch diameter hole passes through the center of the entire OTT shaft and actuator to minimize the exposure of this wiring to oscillatory motions.

The OTT target oscillatory design points are listed in Table 1 , of which, design point \#1 is the most challenging. Table 2 lists the OTT load limits at the tumnel wall which are large enough to accommodate a wide range of model sizes and test conditions.

The OTT also possesses a fast reacting fail-safe braking system to protect a model from excessive acrodynamic forces resulting from uncommanded motion resulting from power or OTT system failures. Figure 3 shows details of the OTT's fail-safe brake system which include a large diameter brake rotor. brake calipers. and limit switches which, when tripped, triggers the brake to prevent model overloading or excessive motion. For personnel safety purposes, the speed of motion of the OTT is limited to approximately 0.5 
Table 1: Performance design points for OTT

\begin{tabular}{lccc}
\hline \hline & $\begin{array}{c}\text { Pitch Inertia. } \\
\text { llom-in }\end{array}$ & $\begin{array}{c}f . \\
\mathrm{H}_{z}\end{array}$ & $\begin{array}{c}|\alpha|, \\
\text { deg }\end{array}$ \\
\hline Design Point \#1 & 65.000 & 40 & 1 \\
Design Point \#2 & 250.000 & 20 & 1 \\
\hline \hline
\end{tabular}

deg/sec by a flow restriction circuit that is energized while the tumel door is open.

\section{OTT SHAKEDOWN TEST RESULTS}

The OTT has undergone extensive shakedown tests to determine the performance and reliability of all systems during braking conditions, fault conditions, and a wide range of oscillatory conditions up to frequencies of $41 \mathrm{H} \%$ and oscillation amplitudes up to 10 degrees. The inertia model (non-aerodynamic) shown in Fig. 4 porsesses a pitch incrtia of $65.000 \mathrm{lbm}-\mathrm{in}^{2}$ which corresponds to design point \#1 in Table 1 . The inertia model and actuator angular positions were measured using an angular displacement transducer. Also measured was the actuator differential hydraulic pressure, an indication of actuator workload. Table 3 lists the inertial pitching moment for the inertia model and the maximum steady and inertial loads for the two pressure models tested on the OTT.

Using the inertia model described above. performance of the OTT was evaluated through $41 \mathrm{~Hz}$ oscillations and is presented in Fig. 5. This figure presents actuator and inertia model oscillatory amplitude and actuator differential hydraulic pressure amplitude $(\Delta P)$ versus frequency for a one-degree sinusoidal oscillation actuator command. Referring to the actuator and differential pressure amplitude in Fig. 5. the actuator angular amplitude is shown to be nearly one degree through $36 \mathrm{~Hz}$, at which frequency the hydraulic system reaches its maximum pressure of 3000 psi. As expected, the actuator cannot maintain the commanded one degree amplitude oscillation beyond $36 \mathrm{~Hz}$. However. beyond $20 \mathrm{~Hz}$ the model angular amplitude exceeds the actuator amplitude. ultimately reaching $1.8^{\circ}$ at $36 \mathrm{~Hz}$. The difference between the model and actuator amplitude is due to torsional wind-up of the OTT shaft under high dynamic torque. Therefore. Fig. 5 shows that the OTT oscillatory performance requirement listed in Table 1 for design point \#1 is met, albeit, in the presence of shaft wind-up. This highlights the importance of locating an angular displacement transducer as near to the model as possible to accurately measure its motion.

Another concern due to the unique oscillatory capabilities of the OTT. is the vibration experienced in the vicinity of the OTT during oscillations. Stress anal$y$ ses of the platform and test section have identified an $\mathrm{bg}$ amplitude limit on all platform vibrations for
Trble 2: Maximum steady OTT loads at tumnel wall

\begin{tabular}{cc}
\hline Load & Maximum Value \\
\hline Lift Force & $2.400 \mathrm{lbf}$ \\
Pitching Moment & $32.000 \mathrm{in-lbf}$ \\
Rolling Noment & $79.000 \mathrm{in}-\mathrm{lbf}$ \\
Yawing Noment & $2.700 \mathrm{in-lbf}$ \\
\hline \hline
\end{tabular}

inf nite fatigue life. Figure 6 presents viloration ampli ude data in $\mathrm{g}$ 's versus OTT oscillatory frequency at vat ious locations in the vertical $(\mathrm{Z})$, lateral (Y). and ax al (X) directions with respect to the OTT shaft. $\mathrm{Pli}$ tform vibrations are seen to reach a maximum of $5.5 \mathrm{~g} s$ at $37 \mathrm{~Hz}$ in the lateral direction and maximum O? T bearing housing vibrations were $3.6 \mathrm{~g}$ s at $41 \mathrm{~Hz}$ in he lateral direction. TDT test section wall vibratio ss were all below $1.5 \mathrm{~g}$ s through $41 \mathrm{~Hz}$. As seen in ig. 6, all vibration levels on the platform were less thi n the $8 \mathrm{~g}$ limit. However, monitoring of platform vil rations is required for OTT oscillatory testing.

\section{OTT UNSTEADY PRESSURE MODEL TEST RESULTS}

Pransonic unsteady pressure measurements have be' nacquired on two wind-tunnel models that underwe it pitch oscillations on the OTT in the test section of the TDT. Each model was used to address a sp eific aspect of OTT performance and to acquire a da abase of unsteady pressures at subsonic and transoric speeds. These tests were designed to quantify $\mathrm{O}^{-} \mathrm{T}$ performance, reliability, and operational procedu es under realistic research conditions and also to de nonstrate model instrumentation techniques under the extreme operating conditions of the OTT. Both wiıd-tumnel models were instrumented with in-situ prissure transducers and accelerometers and an angu ar displacement transducer was used to measure me del position during OTT oscillations.

The first model, known as the Benchmark Supercri ical Wing (BSCW), is a rectangular semispan wing wi $h$ a supercritical airfoil and was tested at frequen(is : up to $30 \mathrm{~Hz}$ that challenged the capabilitios of the O'T to oscillate a model at high frecpuencies. Figure 7 : how's the BSCW model disassembled and highlights th: unsteady pressure transducer locations. Figure $b$ sh: ws the BSCW model and splitter plate mounted in th: TDT test section. Aerodynamic and inertial loads for this model are listed in Table 3 and are moderate. Tle second model tested was a large model of a supe sonic transport configuration known as the Rigid Se nispan Model (RSM) which is shown in Fig. 9. Tle maximum RSM steady aerodynanic lift listed in Table 3 is near to the lift force limit for the OTT listed in Table 2. The RSM was oscillated at frequencies up to $10 \mathrm{~Hz}$ and was intended to test the OTT's alsility to 
Table 3: Maximum model aerodynamic and inertial loads at wing root about the axis of oscillation

\begin{tabular}{cccc}
\hline \hline & $\begin{array}{c}\text { Steady Lift } \\
\text { Force, lbf }\end{array}$ & $\begin{array}{c}\text { Steady Pitching } \\
\text { Moment, in-lbf }\end{array}$ & $\begin{array}{c}\text { Inertial Pitching } \\
\text { Moment, in-lbf }\end{array}$ \\
\hline Inertia Model & $\mathrm{N} / \mathrm{A}$ & $\mathrm{N} / \mathrm{A}$ & $185,452 \mathrm{\omega} \mathbf{\mathrm { i }} 4 \mathrm{H} z$ \\
BSCW & 591 & 1,234 & $1,377030 \mathrm{~Hz}$ \\
RSM & 2,268 & 16.965 & $15,143010 \mathrm{~Hz}$ \\
\hline \hline
\end{tabular}

oscillate a large model in the presence of large steady aerodynamic loads at moderate frequencies.

Unsteady pressure results for both the BSCW and RSM will be presented in plots of mean pressure coefficient $\left(\mathrm{C}_{\mathrm{p}}\right)_{\text {mean }}$ and real (in-phase) and imaginary (out-of-phase) components of pressure coefficient normalized by oscillation amplitude, $\left(\mathrm{C}_{\mathrm{p}}\right)_{\mathrm{Re}} / \mathrm{deg}$ and $\left(C_{p}\right)_{I m} /$ deg, versus non-dimensionalized chordwise location $(\mathrm{x} / \mathrm{c})$. Such data will be presented for various angles of attack $(\bar{\alpha})$ and angular amplitudes $(|\alpha|)$ for oscillatory frequencies $(f)$ up to $30 \mathrm{~Hz}$. Real and imaginary components of pressure coefficient were obtained from a discrete Fourier transform of pressure coefficient time histories at the oscillatory frequency. Time histories of normalized pressure coefficient at chosen chordwise locations will be presented to illustrate the flow characteristics while the model was undergoing oscillations on the OTT.

\section{BSCW/OTT Test Results}

Transonic unsteady pressure measurements have been made on the BSCW while undergoing pitch oscillations at frequencies up to $30 \mathrm{~Hz}$ on the OTT. The BSCW has been previously tested at the TDT as part of the Benchmark Models Program (Refs. 9-10). The BSCW model has at 32 inch span. 16 inch chord, and a NASA SC(2)-0414 airfoil. The OTT pitch axis was located at $\mathrm{x} / \mathrm{c}=0.3$. The spanwise, in-plane, and torsional natural frequencies of the model and support strut were determined to be 24.1, 27.0. and $79.9 \mathrm{~Hz}$. respectively. These natural frequencies dictated decreased oscillation amplitudes at 20 and $30 \mathrm{~Hz}$ and the deletion of testing at $25 \mathrm{~Hz}$.

Using 40 in-situ transducers. unsteady pressure measuremonts were made along the chord at the 60 percent spanwise location at Mach numbers (M) ranging from 0.4 to 0.85 and dynamic pressures (Q) of 100 , 170 , and 200 psf in R-134a heavy gas. Boundary-laver transition was fixed at 7.5 percent chord using a \#30 grit strip. Figures 10-15 will present BSCW unsteady pressure results measured during oscillations on the OTT for $f=1,5,10,15,20$, and $30 \mathrm{~Hz}$, for $|\alpha|=0.18^{\circ}$ to $1.0^{\circ}$. and for $\bar{\alpha}=0^{\circ}$ and $\bar{\alpha}=5^{\circ}$. These oscillations correspond to reduced frequencies from 0.01 to 0.27 for the BSCW. To illustrate the progression of varying degrees of flow nonlinearity, results will be presented at
Mach numbers of $0.5,0.7$, and 0.85 representing sul)sonic, moderately transonic, and highly transonic flow. The results are intended to highlight the capabilities of the OTT for the measurement of unsteady pressure data at high frequencies up to transonic conditions.

To illustrate the consistency of OTT oscillations about a mean angle of attack over a large range of test conditions, plots of mean pressure coefficient are presented in Figs. 10-12. These figures illustrate the $\left(\mathrm{C}_{\mathrm{p}}\right)_{\text {mean }}$ distributions measured during oscillations at frequencies of $0,5,10,15,20$, and $30 \mathrm{~Hz}$ at $\bar{\alpha}=0^{\circ}$ and $\bar{\alpha}=5^{\circ}$. Figure 10 presents mean pressure coefficient data for test section conditions of $\mathrm{M}=0.5$ and $\mathrm{Q}=100 \mathrm{psf}$. In this figure, the $\left(\mathrm{C}_{\mathrm{p}}\right)_{\text {mean }}$ distributions for the group of oscillation frequencies at each $\bar{\alpha}$ are identical as expected if the mean angle of attack did not drift during oscillations, the oscillations were consistently sinusoidal, and the oscillation amplitude was sufficiently small. These subsonic pressure coefficient distributions are void of separated flow and shocks. and are examples of linear flow cases.

For $\mathrm{M}=0.7$ and $\mathrm{Q}=170$ psf, Fig. 11 shows that the $\left(C_{p}\right)_{\text {mean }}$ distributions are identical for the group of oscillation frequencies at each mean angle of attack. The $\left(\mathrm{C}_{\mathrm{p}}\right)_{\text {mean }}$ distribution for $\bar{\alpha}=5^{\circ}$ in Fig. 11 is an example of moderately transonic flow in which some nonlinear effects would be expected to appear.

The flattened upper surface pressure coefficient distribution and the presence of a weak shock on the upper surface are characteristics of a supercritical airfoil at transonic: speeds and are evident in Fig. 12 for $\mathrm{M}=0.85$ and $\mathrm{Q}=200$ psf. Shocks create adverse pressure gradients as shown in this figure and it is apparent that for $\bar{\alpha}=5^{\circ}$, a highly nonlinear shock/boundarylayer separated flow case exists. At a given mean angle of attack, $\left(\mathrm{C}_{\mathrm{p}}\right)_{\text {mean }}$ distributions for each frequency of oscillation are identical or nearly identical in Fig. 12 except in the vicinity of shocks which have a small localized effect on $\left(C_{p}\right)_{\text {mean }}$. These effects can be expected since the flow in this region is highly nonlinear.

For the oscillations of the BSCW model discussed above, the mean model position during uscillations was held to approximately $+1-0.03$ degrees from the steady angle of attack $(f=0)$. Figures $10-12$ provide indirect evidence that the OTT maintained the desired mean angle of attack during oscillations since plots of 
$\left(C_{p}\right)_{\text {mean }}$ are nearly identical for each frequency.

In Fig. 13, real and imaginary components of $C_{p} / \operatorname{deg}$ are presented at $M=0.5$ and $Q=100$ psf for $f=1, \overline{5}, 10,15,20$, and $30 \mathrm{~Hz}$. For this subsonic case, the real, in-phase, components are nearly identical for each oscillatory frequency except 20 and $30 \mathrm{~Hz}$ at which the amplitudes of oscillation were less than at the other frequencies tested. The imaginary, ontof-phase, components of $\mathrm{C}_{\mathrm{p}} / \mathrm{deg}$ in Fig. 13 increase linearly as the oscillatory frequency is increased. Also shown in this figure is a time history of $\mathrm{C}_{\mathrm{p}} / \mathrm{deg}$ for the transducer at $\mathrm{x} / \mathrm{c}=0.1$ on the upper surface for a sicillatory frequency of $1 \mathrm{~Hz}$. It shows a nearly simusoidal response, as expected at subsonic conditions.

Figure 14 presents results at $\mathrm{M}=0.7$ and $\mathrm{Q}=170 \mathrm{psf}$ at $\bar{\alpha}=5^{\circ}$. At this moderately transonic condition, a shock is forming at approximately the $15 \%$ chord as suggested by the adverse pressure gradient in Fig. 11 for $\bar{a}=5^{\circ}$. For each oscillatory frequency, the real components on the lower surface and the aft upper surface of the airfoil are nearly identical, but on the forward 50 percent of the upper surface the real components do not align due to the presence of the shock. As oscillat ory frequency is increased, the imaginary (ontof-phase) components are shown to increase fairly linearly over most of the upper and lower surface of the airfoil. Fig. 14 also presents a time history of $\mathrm{C}_{\mathrm{p}} / \mathrm{deg}$ to illustrate the discontinuity and nonlinearity of the pressure moasured at $\mathrm{x} / \mathrm{c}=0.2$, where a weak shock is moving across this transducer during oscillations.

Figure 15 shows oscillatory components of $\mathrm{C}_{\mathrm{p}} / \mathrm{deg}$ at $\mathrm{M}=0.85$ and $\mathrm{Q}=200 \mathrm{psf}$ for $\bar{\alpha}=5^{\circ}$ and the highly nonlinear aspects of the flow suggested in Fig. 12 are apparent. In Fig. 15, the transonic effects on the flowfield of the BSCW wing are revealed by the peak in $\left(C_{p}\right)_{\text {Re }} / \operatorname{deg}$ at $x / c=0.45$ on the upper surface of the wing where a shock has formed and downstream of which the boundary layer separates. This shock is crossing the upper surface transducer at $\mathrm{x} / \mathrm{c}=0.45$ as shown in the time history of $\mathrm{C}_{\mathrm{p}} / \mathrm{deg}$ shown in Fig. 15. which highlights the nonlinear flow characteristics. Such nonlinear shock dymanics are typical in limit cycle oscillations and flutter at transonic conditions and represent a challenge to unsteady CFD codes. This figure and Figs. 10-14 illustrate the usefulness of the OTT at measuring complex unsteady aerodynamic phenomena on a conventional lifting wing from linear, subsonic flow to highly nonlinear. transonic flow.

\section{RSN/OTT Test Results}

The RSMI model is a semispan supersonic transport model that has a cranked, delta-wing planform and a $4.86 \mathrm{ft}$ semispan and $11.08 \mathrm{ft}$ root chord. Tests of the RSM on the OTT were intended to demonstrate
OT'T capabilities while oscillating a large model at trensonic conditions at high angles of attack. which pruduces large steady and unsteady loads. The maxim min steady loads for the RSM, listed in Table 3 , are qu te large compared to BSCW steady loads. The RS M model was oscillated at frequencies of $1.2,5,8$, an $\mathrm{l} 10 \mathrm{~Hz}$ at Mach numbers of 0.5 to $1.05 \mathrm{in}$ an R13 ta test medium. Mean angles of attack ranged from $-5^{c}$ to $15^{\circ}$ and oscillatory amplitudes, $|\alpha|$. from $0.2^{\circ}$ to $2^{\circ}$. Two hundred in-situ unsteady pressure measus ements at four spanwise locations were acquired on thr model. Unsteady pressure results for the RSM wi 1 be presented for the 60 percent spanwise location (on tboard of the wing crank) at $Q=100$ psf, $\mathrm{M}=0.5$ an $\left\lfloor M=1.05\right.$, and for $\bar{\alpha}=6^{\circ}$ and $12^{\circ}$.

Wean values of pressure coefficient measured during os illations of the RSM at $f=0,2,5.8$, and $10 \mathrm{~Hz}$ and at $\bar{n}=6^{\circ}$ and $12^{\circ}$ are presented in Figs. 16 and 17 for Mich numbers of 0.5 and 1.05 , respectively. The pressu e coefficient distributions presented in these figures ar typical for a supersonic cranked delta wing config tration. in which lift is generated to a large extent by vortices created at the wing leading edge. For $M=0.5$, the mean pressure coefficient distributions at $\bar{\alpha}=6^{\circ}$ and at $\bar{\alpha}=12^{\circ}$ in Fig. 16 are nearly identical for ea h oscillation freculency. At the highly loaded conditions of Fig. 17 (Table 3), $\left(\mathrm{C}_{\mathrm{p}}\right)_{\text {mean }}$ distributions on the upper and lower surface at $\bar{\alpha}=6^{\circ}$ and at $\bar{\alpha}=12^{\circ}$ are ne urly identical for each oscillation frequency. Howev.r. some amplitude and/or frequency effects arise in Fi: 17 for $\bar{a}=6^{\circ}$ on the upper surface possibly due to th: highly vortical flow present.

For the test conditions presented in Figs. 16 and 17 the mean value of model position during oscillaticus did not vary more than $+/-0.03$ degrees from tl]: steady angle of attack $(f=0)$. These figures provic e indirect evidence that the OTT maintained mean an sle of attack during oscillations of the RSM under hig h steady loads since plots of $\left(C_{p}\right)_{\text {mean }}$ are nearly ide ntical for each frequency.

Zeal (in-phase) and inaginary (out-of-phase) compoients of normalized pressure coefficient measured on the RSM are shown in Figs. 18 and 19 at the sanne flow conditions as the previous figures. These res ults are presented to illustrate the OTT's ability to actuire unsteady data on a large model at moderate aul I high steady load conditions. The real componeits of $C_{p} /$ deg shown in Fig. 18 at $M=0.5$ and $\bar{n}=6^{\circ}$ are nearly identical on the entire lower surface and th: upper surface aft of $\mathrm{x} / \mathrm{c}=0.45$. Frequency effects ap sear to arise on the forward upper surface where $\left(C_{,},\right)_{\mathrm{Re}} / \mathrm{deg}$ varies with oscillation frequency and the pe $\mathrm{tk}$ in $\left(\mathrm{C}_{\mathrm{p}}\right)_{\text {Re }} / \mathrm{deg}$ at $\mathrm{x} / \mathrm{c}=0.15$ suggests rortical flow ne: or this location. The imaginary components of $\mathrm{C}_{1} / \mathrm{deg}$ are found to vary quite linearly as oscillatory 
frequency increases, except on the upper surface in the vicinity of $x / c=0.2$. Also, the upper surface imaginary components exhibit a pronounced decrease in magnitude in the vicinity of the presumed vortcx.

Figure 19 shows real and imaginary components of normalized pressure coefficient measured on the RSM at $M=1.05$ and $\bar{\alpha}=12^{\circ}$. At this Mach number, the real and imaginary components are an order of magnitude smaller for each oscillation frequency as compared to values in Fig. 18 at Mach 0.5 , demonstrating wing pressures on the RSM at supersonic conditions are less sensitive to model oscillations than at subsonic conditions. Lower surface real components in Fig. 19 follow the same trend for each frequency. Imaginary components appear somewhat linear with respect to oscillation frequency on the lower surface, but not to the same extent on the upper surface.

An unforeseen interaction between RSM model dynamics and OTT dynamics was encountered at some tunnel conditions at high angles of attack. In particular, for RSM oscillations at $10 \mathrm{~Hz}$ the model's first wing bending mode $(22.5 \mathrm{~Hz})$ was visually observed to be excited. This interaction can be seen in Figs. 20 and 21 which present model angular position and wing outhoard trailing edge acceleration time histories and frequency content. For these figures, tunnel conditions were $\mathrm{M}=1.05$ and $\mathrm{Q}=100 \mathrm{psf}$ and the model was at $\bar{\alpha}=12^{\circ}$ during oscillations at $10.2 \mathrm{~Hz}$ and $5.1 \mathrm{~Hz}$, respectively. In Fig. 20 a small "hitch" in the model position time history can be seen, as the model is pitched downward against large steady aerodynamic loads. Because the model angular position time history is not purely sinusoidal, but rather a periodic: function that can be represented by a Fourier series, higher harmonics of the oscillation frequency must be present. Referring to the FFT of model angular position, the $10.2 \mathrm{~Hz}$ OTT oscillation frequency is clearly shown in addition to a rather large second harmonic at $20.5 \mathrm{~Hz}$. Additionally, the dominant response of the wing is shown by the outboard trailing edge accelerometer to be $20.5 \mathrm{~Hz}$ as shown in the time history and FFT of Fig. 20. The proximity of the second harmonic at $20.5 \mathrm{~Hz}$ to the RSM first bending natural frequency of $22.5 \mathrm{~Hz}$ is the cause of this large wing accelerometer response at $20.5 \mathrm{~Hz}$ in Fig. 20 .

To further illustrate this phenomenon, Fig. 21 presents RSM angular position and outboard trailing accelerometer time histories and FFT's for an oscillation frequency of $5.1 \mathrm{~Hz}$ for which several harmonics are present. The model angular position appears to be purely sinusoidal, but small components of higher harmonics of $5.1 \mathrm{~Hz}$ arise in the frequency content. As discussed above, these higher harmonics are believed to arise due to the high acrodynamic loads present at this condition. In Fig. 21, the fourth harmonic of the
$5.1 \mathrm{~Hz}$ oscillation frequency is seen to excite a $20 . \overline{\mathrm{Hz}}$ response in the outboard trailing edge accelerometer. again due to its proximity to the $22.5 \mathrm{~Hz}$ first wing bending natural frequency. Additional tuning of the OTT closed loop PIDF control system may alleviate this rosponse. However, this phenomenon indicates that model dynamics must be considered when developing a test program which utilizes the OTT to oscillate a large model which may have a relatively low first natural frequency under high aerodynamic loads.

\section{CONCLUSIONS}

A new forced oscillation system, known as the Oscillating Turntable (OTT), has been installed and tested at NASA Langley's Transonic Dynamics Tunnel (TDT). The system has been designed to oscillate sidewall mounted wind-tunnel models instrumented to acquire unsteady pressure and loads data for computational fluid dynamics code validation. Performance testing has shown that the OTT exceeds the original design requirements with respect to oscillatory performance. The hydraulic actuator, hydraulic pump, and digital control system of the OTT have proven reliable during extensive shakedown testing and research model testing. OTT support platform vibrations during high frequency oscillations of the inertia model were shown to be within its design limits.

Two semispan wind-tumnel tests using the OTT have been conducted that involved the Benchmark Supercritical Wing (BSCW) and the supersonic transport wing known as the Rigid Semispan Model (RSM). These tests were intended to further qualify the OTT as a research tool and to obtain unsteady pressure measurements for the validation of unsteady aerodynamic analyses. A subset of unsteady pressure data from these tests has been presented in this paper to highlight OTT performance and its ability to acquire such data at transonic, high frequency, and high-load conditions. Conclusions from these tests include:

1. The OTT successfully oscillated the BSCW at frequencies up to $30 \mathrm{~Hz}$ while holding mean angles of attack.

2. The OTT was proven capable of holding mean angles of attack in the presence of large steady and unsteady aerodynamic loads during oscillations of the RSM at frequencies up to $10 \mathrm{~Hz}$.

4. At transonic conditions for the BSCW, shock dynamics and nonlinear effects were clearly identified which illustrate the usefulness of the OTT at identifying such complex flow phenomena.

5. Instrumentation concepts for OTT testing proved successful during both research tests.

6. Overall performance of the OTT during four weeks of realistic research testing exceeded expectations and test time was used very efficiently. 
7. The potential for interaction between model dynamics and OTT dynamics must be considered.

\section{REFERENCES}

1. Edwards, J.W. and Malone. J.B., "Current Status of Computational Methods for Transonic $\mathbf{L}$ steady Aerodynamic: and Aeroelastic Applications. AGARD Structures and Materials Panel Specialist 's Meeting on Transonic Unsteady Acrodynamics and Aeroelasticity. San Diego, CA. Oct. 1991.

2. Bemmett. R.II., Dansberry. B.E., Farmer. M.G.. Eckstrom. C.V.. Seidel. D.A.. Rivera. J.A., "Transonic Shock-Induced Dynamics of a Flexible Wing with a Thick Circular-Arc Airfoil". NASA TMI-104088. May 1991. .

3. Nixon. D., "Unsteady Transonic Aerodynamics". Vol. 120, Progress in Astronautics and Aeronautics, AIAA, Washington, D.C., 1989.

4. Rainey, A.G., "Neasurement of Aerodynamic Forces for Various Mean Angles of Attack on an Airfoil Oscillating in Pitch and on Two FiniteSpan Wings Oscillating in Bending with Emphasis on Damping in the Stall". NACA Technical Note 3643. May 1956.

5. Davis, S.S., Malcolm, G.N.. "Experiments in Unsteady Transonic Flow". AIAA Paper 79-0769.

6. Davis, S.S., Malcolm, G.N., "Experimental L'nsteady Aerodynamics of Conrentional and Supercritical Airfoils". NASA TM-81221. Aug. 1980.

7. Ricketts. R.H., Sandford. M.C.. Seidel. D.A., and Watson. J.J.. "Transonic Pressure Distributions on a Rectangular Supercritical Wing Oscillating in Pitch". AIAA Journal of Aircraft, Vol. 21, No. 8. Aug. 1984.

8. Cumningham. A. M.. Jr. and den Boer, Ruud D., "Overview of Unsteady Transonic Wind Tunnel Test on a Semispan Straked Delta Wing Oscillating in Pitch". Wright Laboratory, Flight Dynamics Directorate, WL-TR-94-3017, Aug. 1994.

9. Bennett. R.M.. Eckstrom. C.V.. Rivera. J.A.. Dansberry, B.E., Farmer. M.G.. Durham. M.H., "The Benchmark Aeroelastic Models ProgramDescription and Highlights of Initial Results". NASA TM-104180, December. 1991.

10. Danslyerry, B.E.. Durham, M.H.. Bennett. R.AI.. Rivera, J.A., Silva. W.A.. and Wieseman. C.D.. "Experimental Unisteady Pressures at Flutter on the Supercritical Wing Benchmark Model". Presented at the AIAA/ASME/ASCE/AHS/ASC 34th Structures, Structural Dynamics, and Materials Conference, La Jolla, California, April. 1993.

11. Rivera, J.A., Dansberry; B.E.. Bennett. R.M.. Durham, M.H., and Silva, W.A., "NACA0012 Benchmark Model Experimental Flutter Results with Lnsteady Pressure Distributions". NASA TM-107581, March, 1992.

12 Cole, S.R. and Garcia. J.L.. "Past, Present, and Future Capabilities of the Transonic Dynamics Tumnel from an Aeroelasticity Perspective". Presented at the AIAA Dynamics Specialists Conference. Atlanta. GA. April 5-6. 2000.

\section{FIGURES}

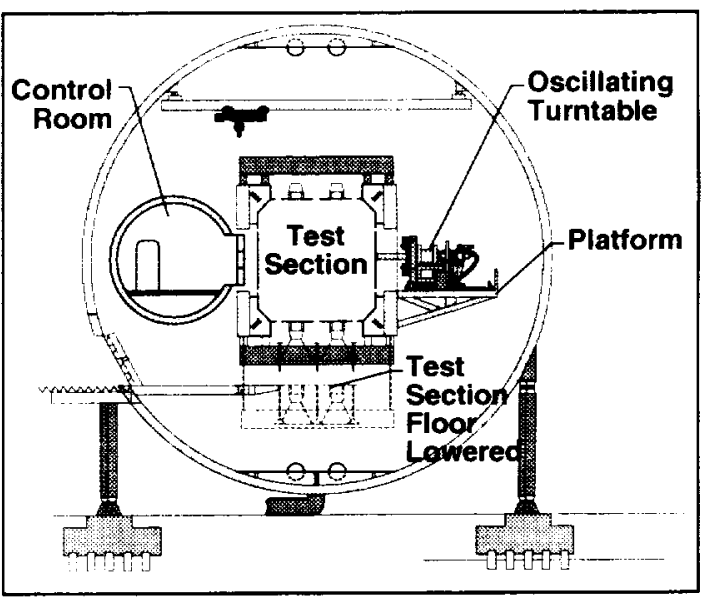

$\mathrm{Fi}_{\xi}$ ure 1: Cross section of TDT showing test section an 4 location of OTT.

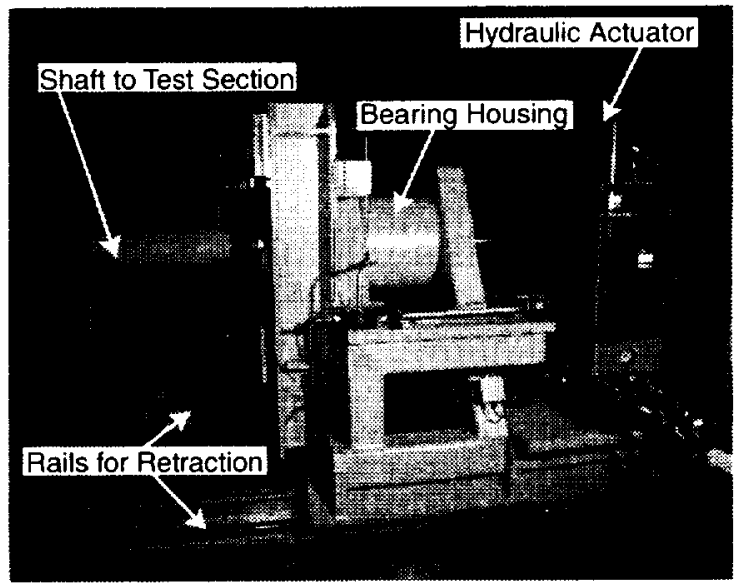

Figure 2: Side view of OTT. 


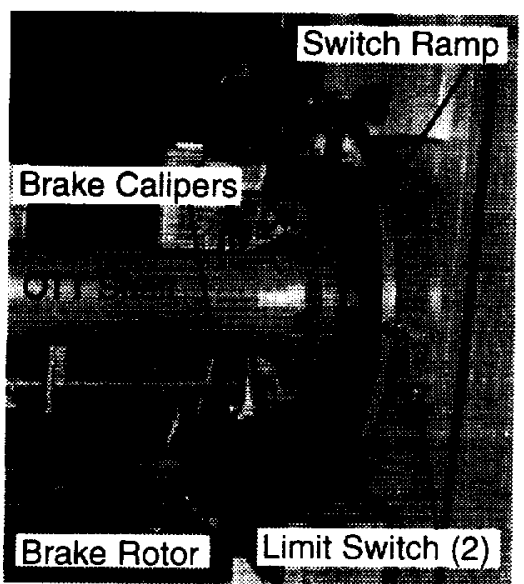

Figure 3: OTT brake components.

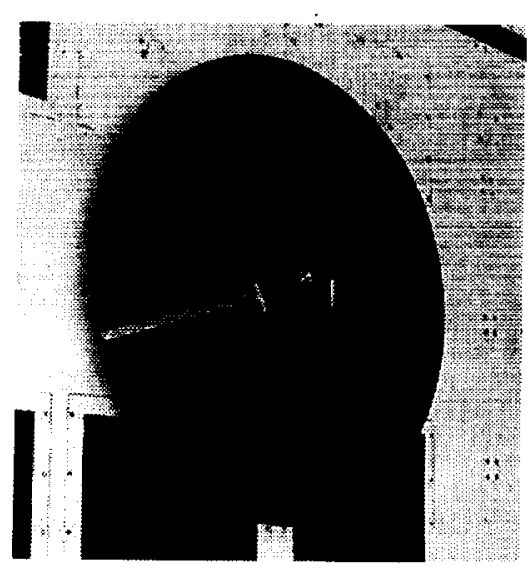

Figure 4: Inertia model used during OTT shakedown testing.

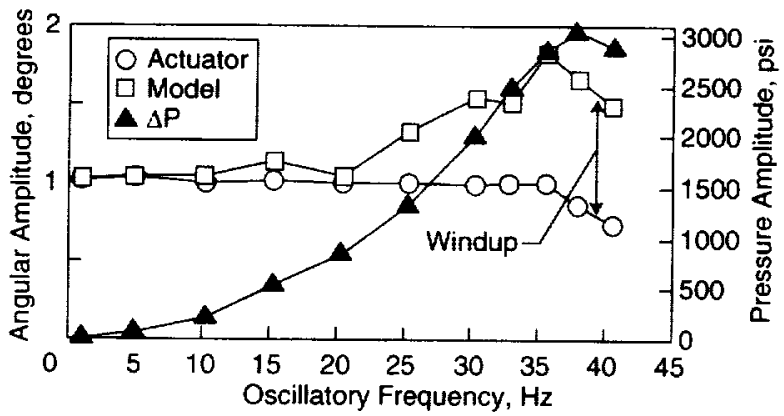

Figure 5: OTT performance data with inertia model.

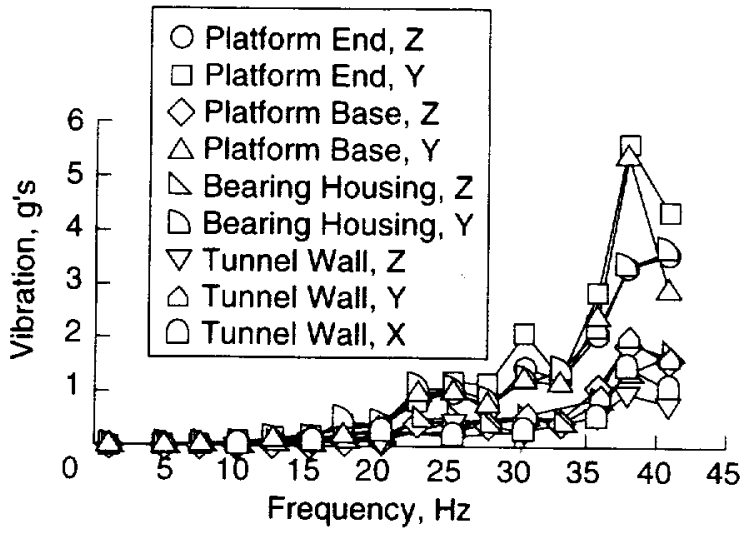

Figure 6: Platform, OTT, and tumnel wall vibrations during oscillation of inertia model.

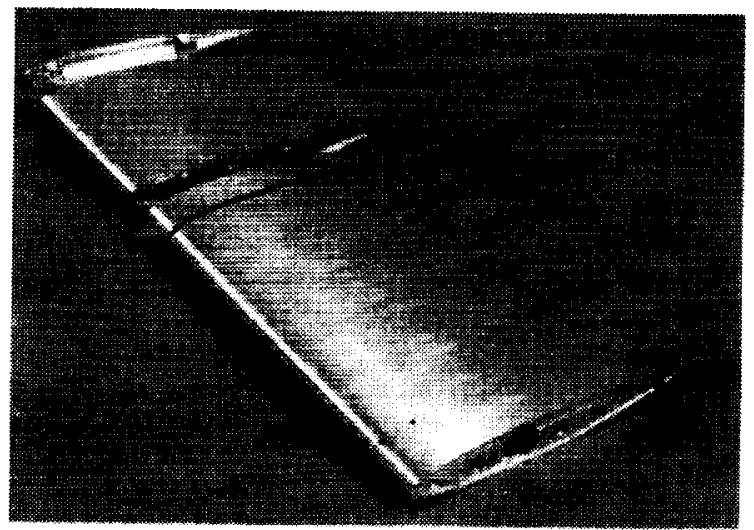

Figure 7: BSCW model (disassembled) with transducer locations highlighted.

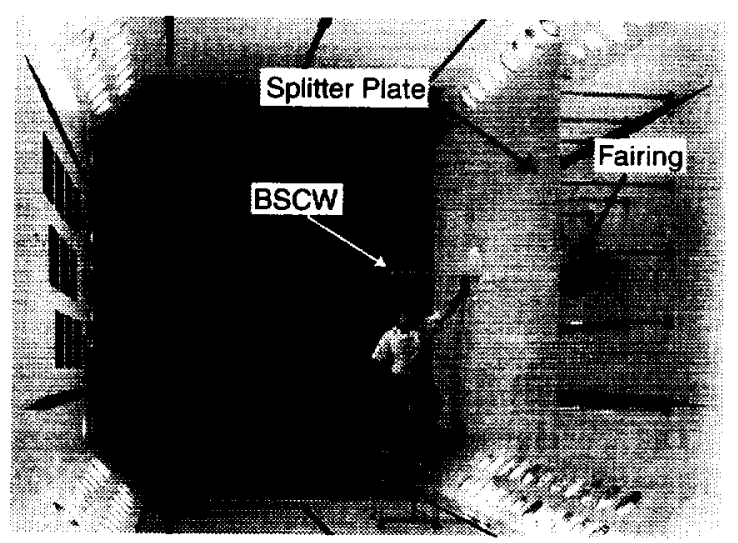

Figure 8: BSCW model mounted in TDT test section. 


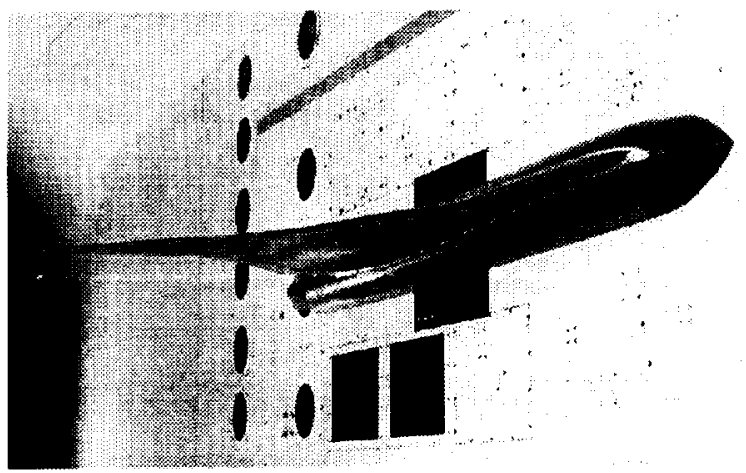

Figure 9: RSM on the OTT.

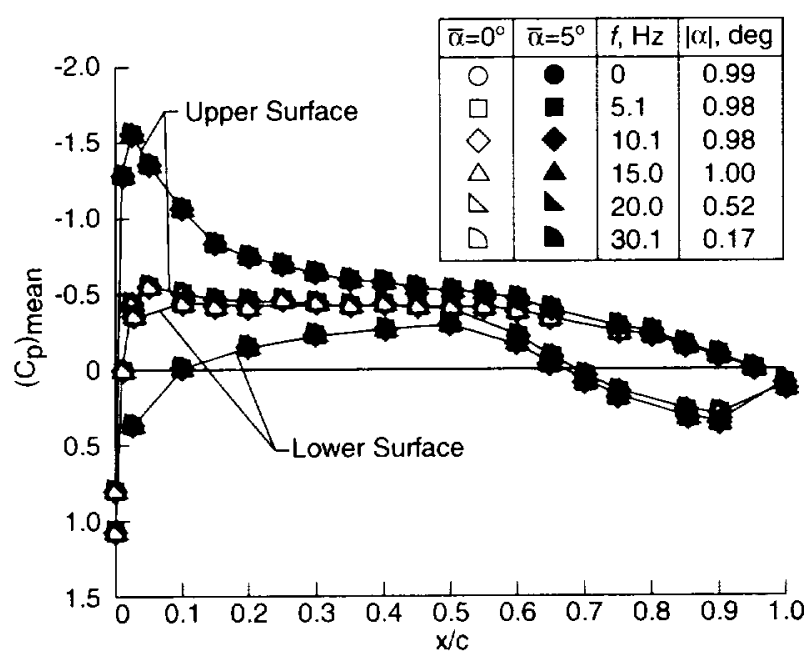

Figure 10: BSCW mean pressure coefficient distributions for $\bar{a}=0^{\circ}$ and $5^{\circ}$ at $\mathrm{M}=0.5$ and $Q=100 \mathrm{psf}$.

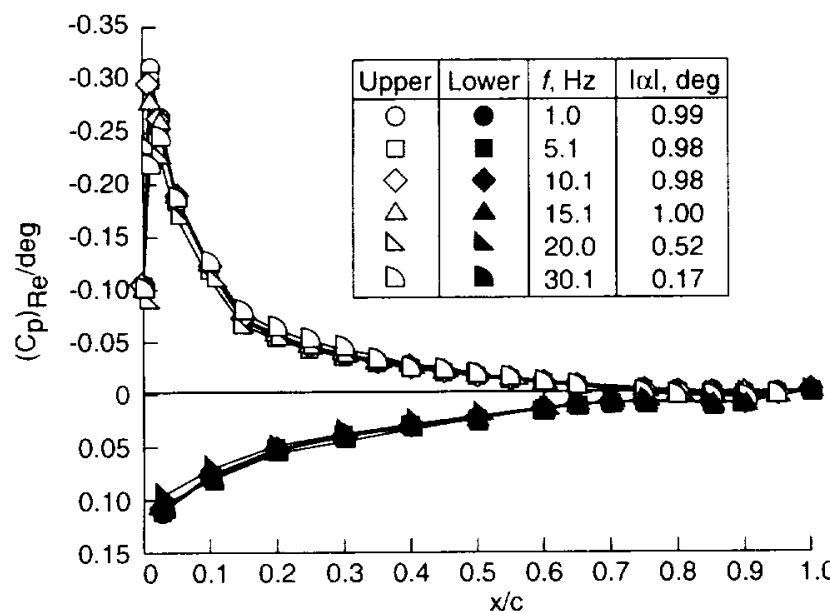

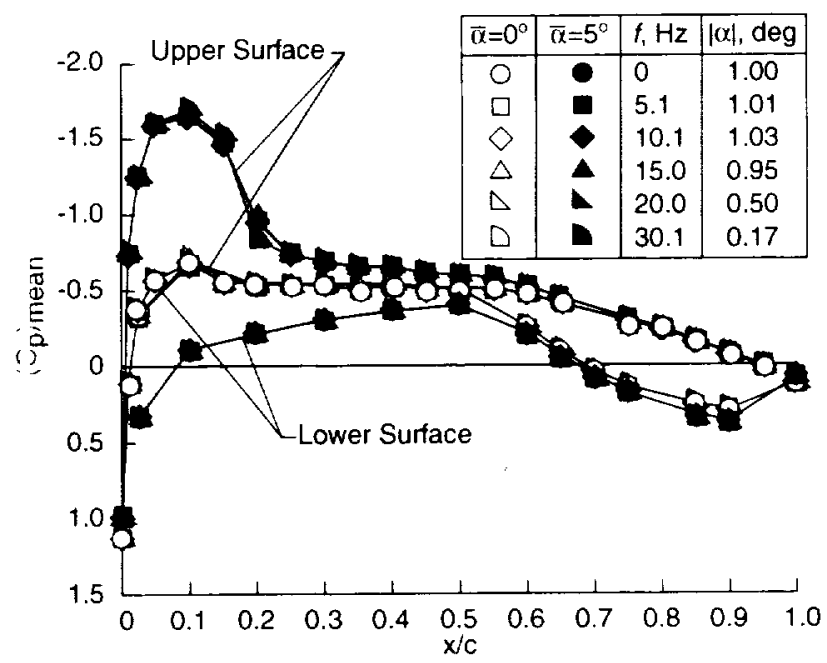

I igure 11: BSCW mean pressure coefficient distribu$t$ ons for $\bar{\alpha}=0^{\circ}$ and $5^{\circ}$ at $\mathrm{M}=0 . \bar{\tau}$ and $Q=17() \mathrm{psf}$.

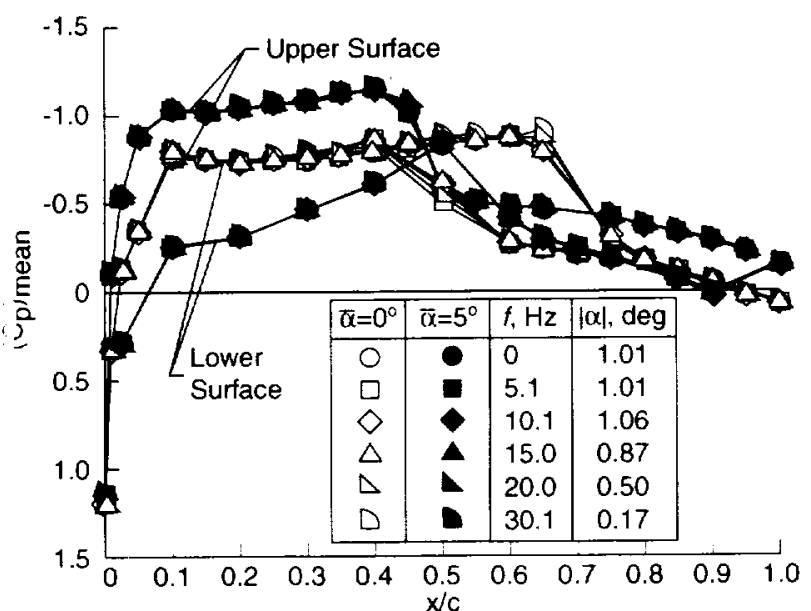

l igure 12: BSCW mean pressure coefficient distributions for $\bar{\alpha}=0^{\circ}$ and $5^{\circ}$ at $\mathrm{M}=0.85$ and $\mathrm{Q}=200 \mathrm{psf}$.

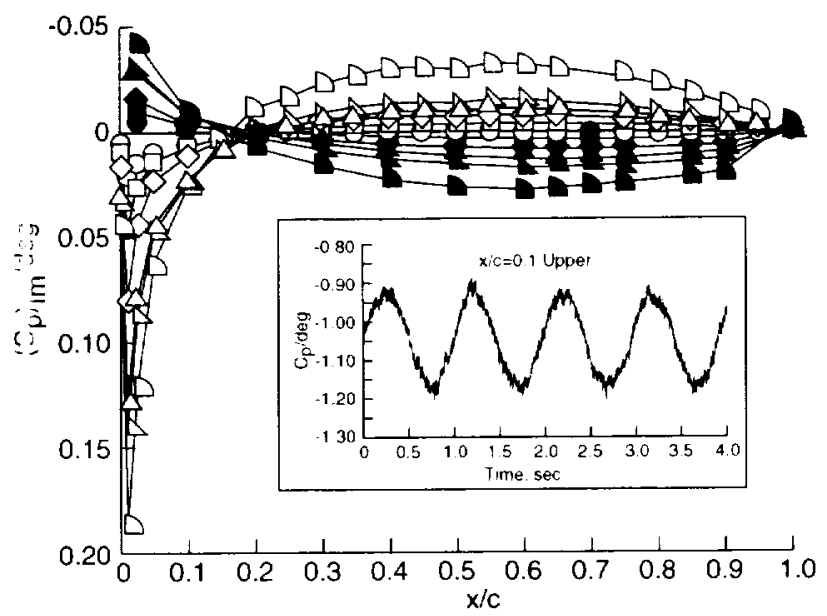

Figure 13: BSCW $\left(C_{p}\right)_{\text {Re }} / \operatorname{deg}$ and $\left(C_{p}\right)_{\operatorname{mon}} / \operatorname{deg}$ dis: ributions for $\mathrm{II}=0.5$ and $\mathrm{Q}=100 \mathrm{psf}$ for $\bar{n}=5^{\circ}$. 

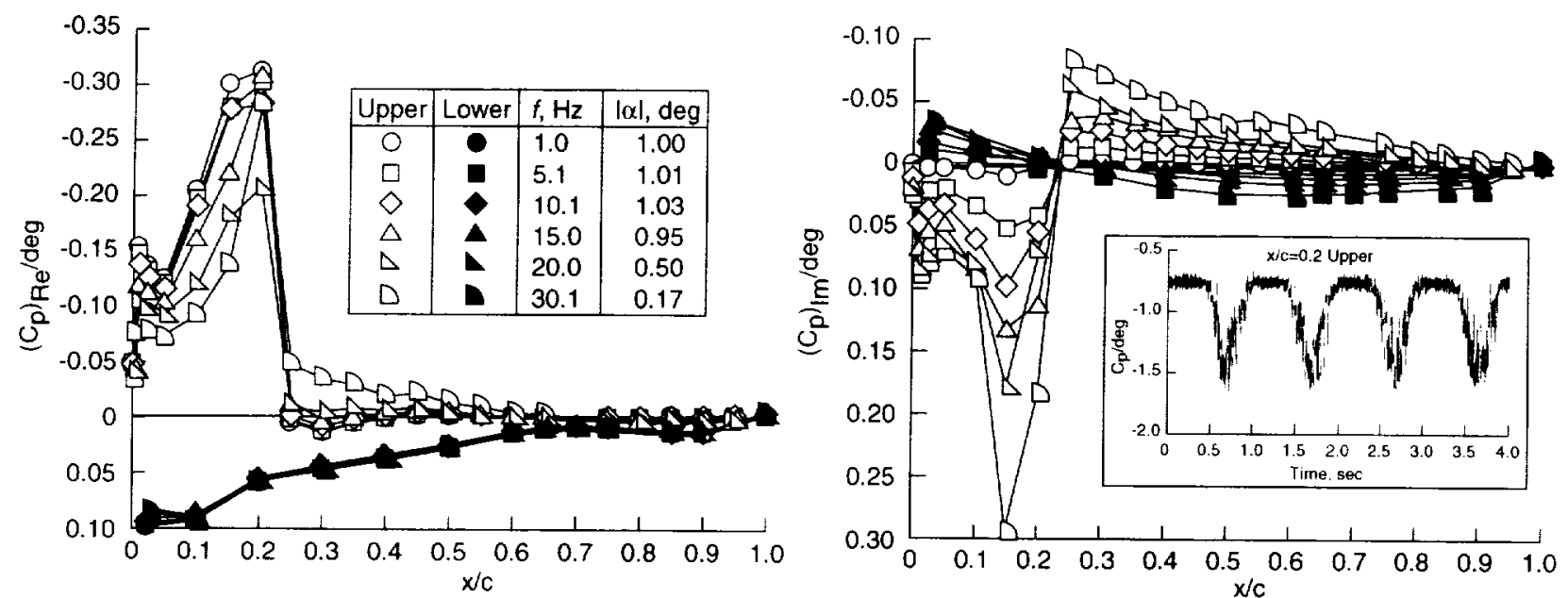

Figure 14: BSCW $\left(C_{\mathrm{p}}\right)_{\mathrm{Re}} / \mathrm{deg}$ and $\left(\mathrm{C}_{\mathrm{p}}\right)_{\mathrm{lm}} / \mathrm{deg}$ distributions for $\mathrm{M}=0.7$ and $\mathrm{Q}=170 \mathrm{psf}$ for $\bar{\alpha}=5^{\circ}$.
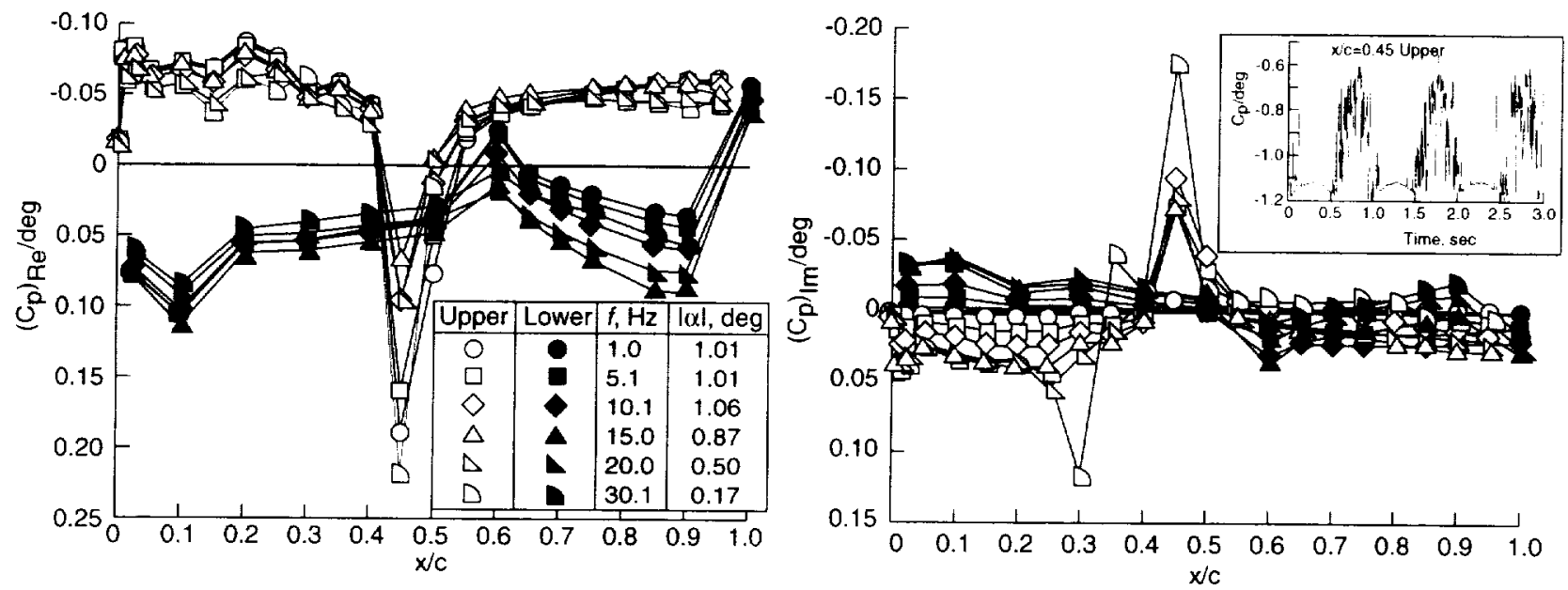

Figure 15: $B S C W\left(C_{p}\right)_{\operatorname{Re}} / \operatorname{deg}$ and $\left(C_{p}\right)_{\operatorname{lm}} /$ deg distributions for $M=0.85$ and $Q=200$ psf for $\bar{c}=5^{\circ}$.

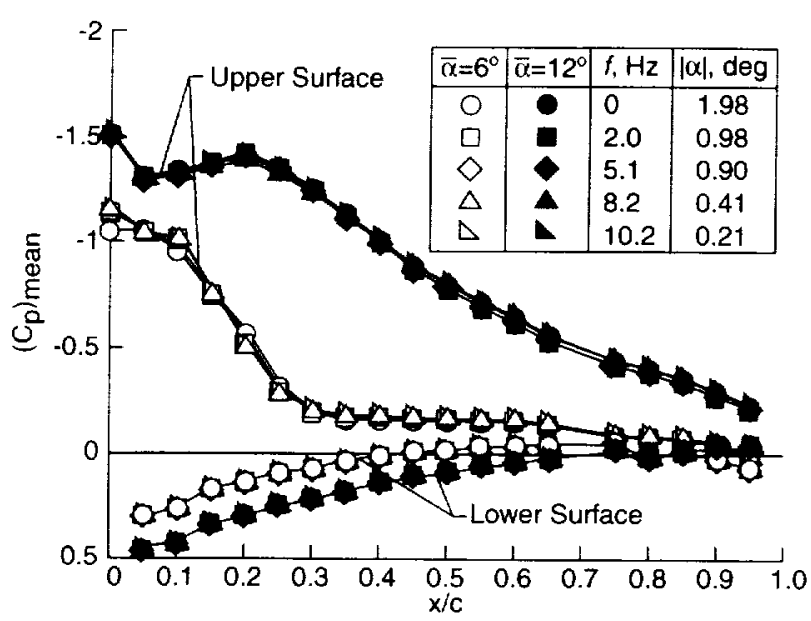

Figure 16: RSM mean pressure coefficient distributions for $\bar{\Omega}=6^{\circ}$ and $12^{\circ}$ at $M=0.5$ and $Q=100$ psf.

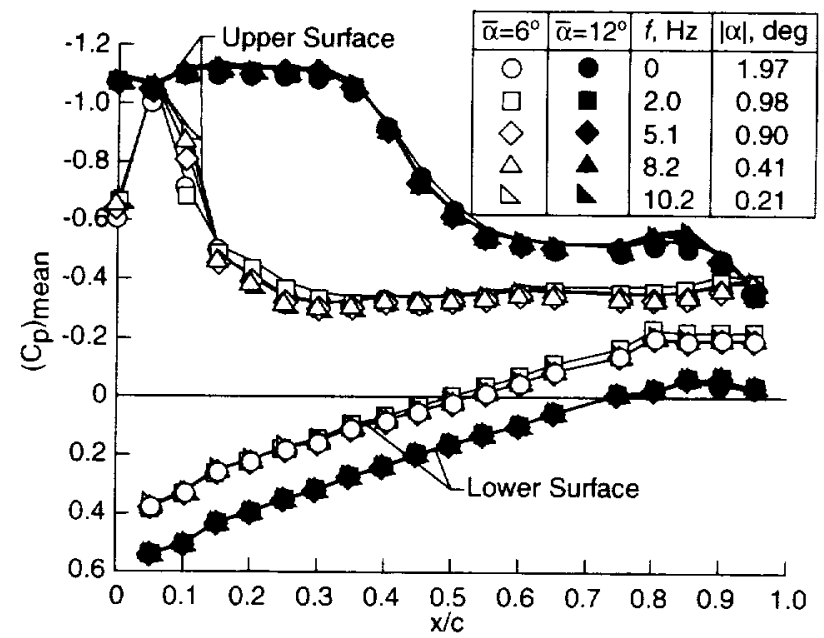

Figure 17: RSM mean pressure coefficient distributions for $\bar{\alpha}=6^{\circ}$ and $12^{\circ}$ at $\mathrm{M}=1.05$ and $Q=100 \mathrm{psf}$. 

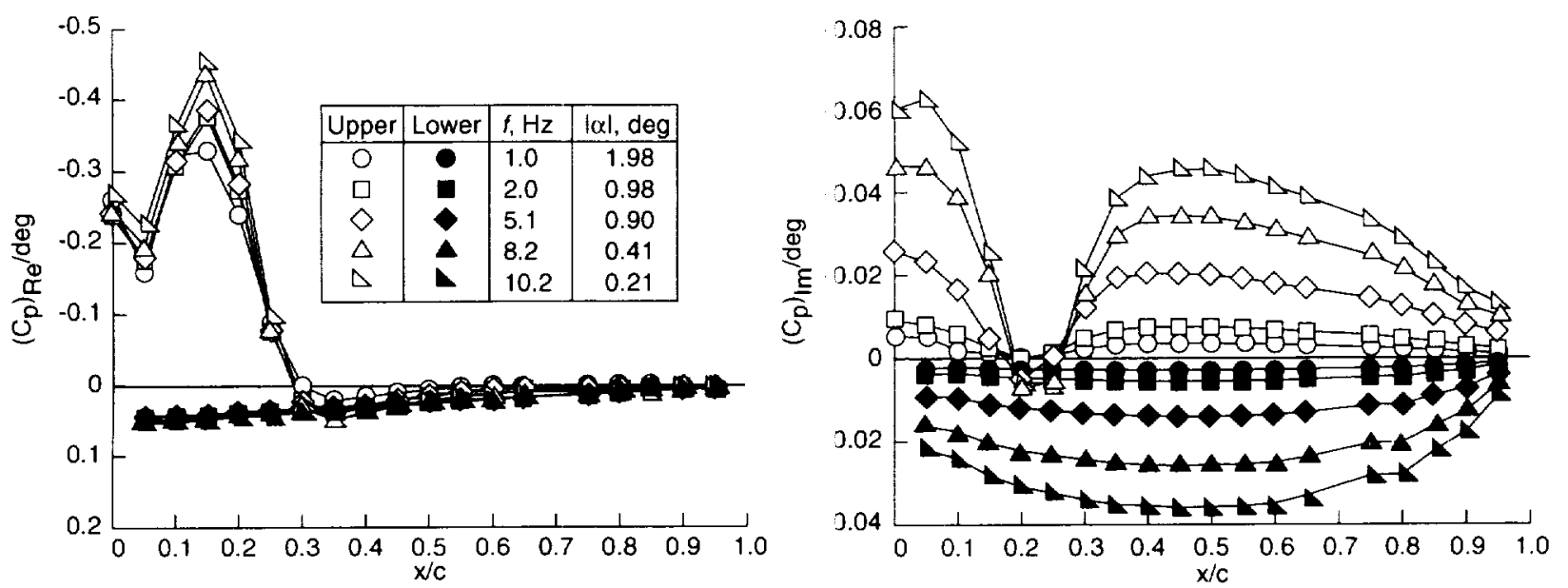

Figure 18: RSM $\left(C_{p}\right)_{\operatorname{Re}} / \operatorname{deg}$ and $\left(C_{p}\right)_{1 m} / \operatorname{deg}$ distri utions for $M=0.5$ and $Q=100$ psf for $\bar{n}=0^{\circ}$.

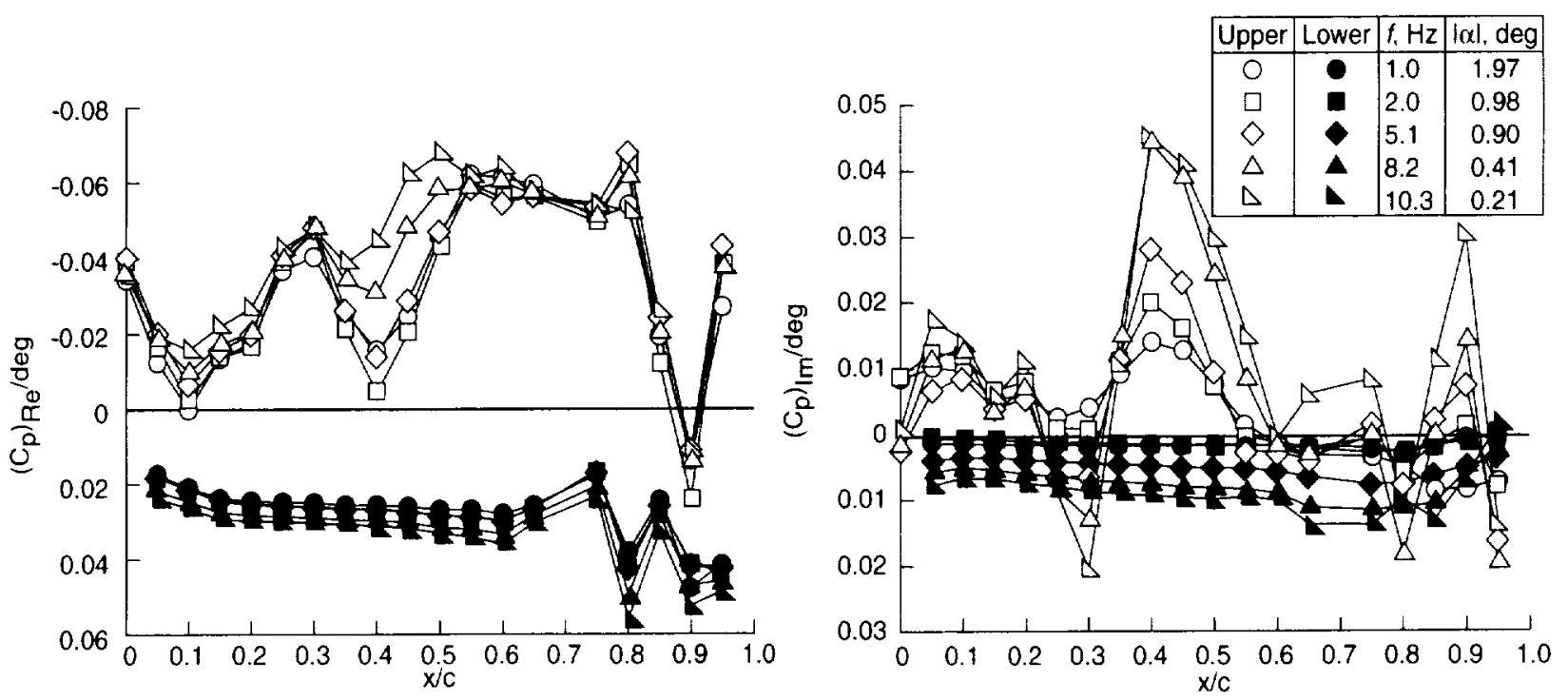

Figure 19: RSM $\left(C_{p}\right)_{\text {Re }} / \operatorname{deg}$ and $\left(C_{p}\right)_{\text {m }} / \operatorname{deg}$ distri utions for $M=1.05$ and $Q=100$ psf for $\bar{n}=12^{\circ}$.

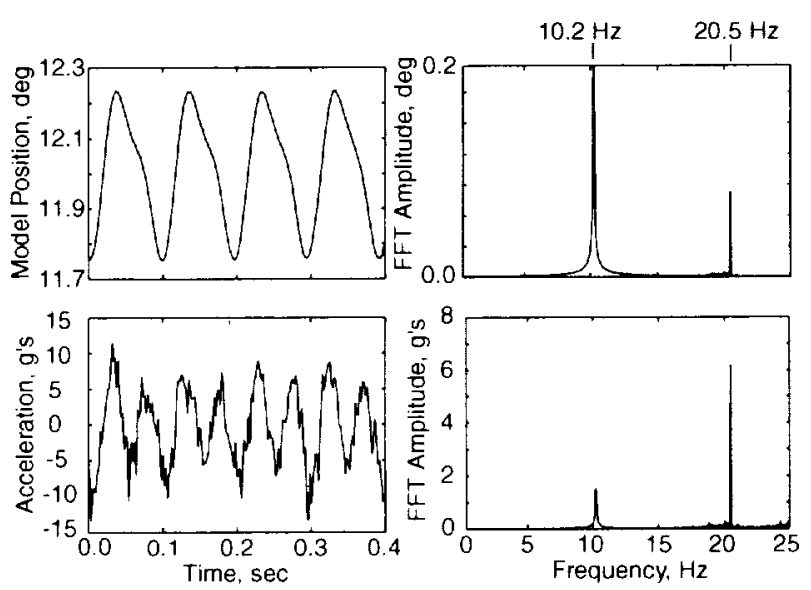

Figure 20: Time history and FFT of RSM model angular position and wing outboard trailing edge acceleration at $\mathrm{M}=1.05 . \bar{a}=12^{\circ}$, and $f=10.2 \mathrm{~Hz}$.

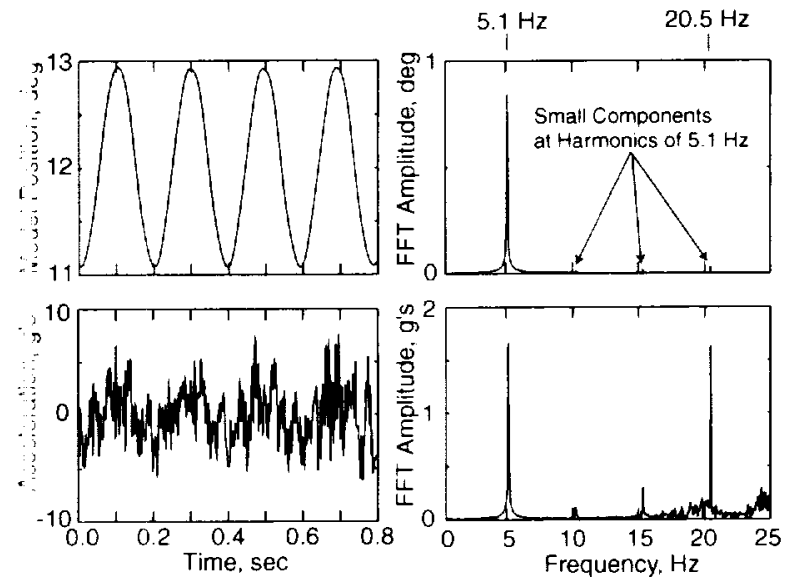

I igure 21: Time history and FFT of RSM model angular position and wing outboard trailing edge accelcration at $\mathrm{X}=1.05 . \overline{\mathrm{n}}=12^{\circ}$. and $f=5.1 \mathrm{~Hz}$. 

The following papers have been DAA approved as Lnclassified, Publicly Available documents and are available on the Langley Technical Reports ؛ erver (LTRS):

\section{Meeting Presentations:}

40th AIAA Aerospace Sciences Meeting \& Exhibit, 1/14-17/2002, Reno, NV:

R. DeLoach, et al: Fractional Factorial Experiment Designs to Min...AIAA 2002-0746

R. DeLoach: Tactical Defenses Against Systemitic Variation in Wind...AIAA 2002-0885

M.K. Smart, et al.: Computational Investigation of the Performance...AIAA 2002-0508

J. Lacey, et al.: Improvement of Flow Quality in NAL CHOFU Mach...AIAA 2002-0440

A.F. Tinetti, et al:: Reduction of Wake-Stator Interaction Noise Using...AIAA 2002-1036

D.J. Piatak, et al.: A New Forced Oscillation Capability for the Trans...AIAA 2002-0171

J.M. Luckring, et al.: Reynolds Number and Leiding-Edge Bluntness...AIAA-2002-0419

J.C. Vassberg, et al:: Drag Prediction for the DLR-F4 Wing/Body...AIAA-2002-0840

P.A. Parker, et al:: Structural Optimization of a l'orce Balance Using a ...AIAA 2002-0540

D.W. Levy, et al: Summary of Data From the First AIAA CFD Drag...AIAA-2002-0841

M.M. Curtin, et al.: Investigation of Transonic Feynolds Number...AlAA 2002-0420

43rd AIAA/ASME/ASCE/AHS/... Stru, Struc'l Dyn \& Matls. Conf., 4/22-25/2002/, Denver, CO:

T. Chen, et al: Coupling Finite Element and Meshless Local Petrov...AIAA 2002-1659

W.A. Silva, et al:: Development of Reduced-Order Models for Aero...AIAA 2002-1596

G.M. Odegard, et al.: Constitutive Modeling of Nanotube-Reinforced....AIAA 2002-1427

R.C. Scott, et al: : Measurement of Unsteady Pre ssure Data on a Large...AIAA2002-1648

J.R. Reeder, et al.: Postbuckling and Growth of Delaminations in Comp...AIAA 2002-1746

D.C. Jegley: Structural Efficiency of Stitched Composite Panels with...AIAA 2002-1728

AHS Aerodynamics, Acoustics \& Test Evaluation Meeting, 1/23-25/2002, San Francisco, CA:

K.S. Brentner, et al:: Maneuvering Rotorcraft Noise Prediction: A New Code for a...

SPIE's Annual Int'l Symp. on Smart Structures \& Naterials, 3/17-21/2002, San Diego, CA:

C.L. Lach, et al.: Effects of Thermomechanical History on the Tensile Behavior...

T.L. Turner: Structural Acoustic Response of a SMA Hybrid Composite Panel.

39th AIAA Aerospace Sciences Meetings \& Exhibi1, 1/8-11/2001, Reno, NV:

R.A. Wahls: The National Transonic Facility: $A$ Research...(AIAA 2001-0754) 
